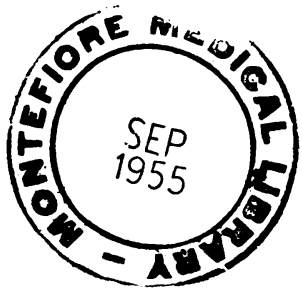

\title{
TUBERCULOUS MENINGITIS OF ACUTE ONSET
}

\author{
BY \\ K. B. TAYLOR,* H. V. SMITH, and R. L. VOLLUM \\ From the Departments of Neurology and Bacteriology, Radcliffe Infirmary, Oxford
}

The classical descriptions of tuberculous meningitis all emphasize the insidious onset as one of the chief characteristics of the disease. Modern experience has amply confirmed this. For example, in a series of 55 young Servicemen treated at the Military Hospital for Head Injuries, Wheatley, and for whom a full history was obtained, 43 had been ill for over one week and 15 for over three weeks before admission to hospital (Taylor, 1954). At the same time, we have occasionally seen cases in which the onset, so far from being insidious, has been acute or even abrupt (Smith and Vollum, 1954 ; Case 1). As these cases have accumulated so we have come to recognize that they resemble each other in several respects besides the onset; in particular, early in the illness the cell counts in the cerebrospinal fluid (C.S.F.) are unusually high; the symptoms often remit very rapidly, sometimes even before treatment is begun; on the whole, the prognosis is good.

These cases therefore appear to form a small but definite group within the series as a whole. But, though rare, they are of some importance both because the unusual history and C.S.F. findings tend to confuse the diagnosis, and because they throw some light on the pathogenesis of the C.S.F. changes in tuberculous meningitis in general.

\section{Incidence}

In a series of 200 consecutive unselected cases of tuberculous meningitis treated at the Military Hospital for Head Injuries, Wheatley, and at the United Oxford Hospitals, there are eight in which the patients had been ill for less than one week when admitted to hospital and in which the C.S.F. was found to contain 500 cells per c.mm. or more at least once before treatment was begun. A ninth case (Case No. 118), in which the patient died on the tenth day of illness, has been included on clinical grounds, even though the C.S.F. findings were not

\footnotetext{
* Working with a grant from the Medical Research Council.
}

typical. The diagnosis was confirmed in all cases by identification of $M$. tuberculosis in the C.S.F.

A minimal count of 500 cells per c.mm. was arbitrarily chosen as a criterion for inclusion in this group because it is often accepted as the upper limit for cell counts in tuberculous meningitis (Merritt and Fremont-Smith, 1937). Had the minimum been set a little lower, e.g., at 450 cells per c.mm., a few more cases would have been included. The syndrome under discussion was thus seen in at least $4 \%$ of all cases.

\section{The Clinical Picture}

The relevant findings in these cases are summarized in Table I. The patients varied in age between 6 and 36 years; one was female and the rest were males. This apparent sex difference is simply a reflexion of the preponderance of males in the series as a whole, due to the fact that Servicemen as well as civilians are treated at this centre.

In all cases the patients became so rapidly and so obviously unwell that they were admitted to hospital some time during the first week of their illness. The departure from normal health was usually so abrupt that the interval between the onset of symptoms and admission to hospital can be calculated with fair accuracy. Several patients were first admitted to hospitals elsewhere and later transferred to us for diagnosis and treatment, and the day of the disease on which treatment was begun corresponds with the time at which the diagnosis was made.

Table I also shows the stage the disease had reached at the outset of treatment (Medical Research Council Report, 1948). In four cases the disease was still in the " early" stage ; that is to say, the patients were fully conscious and rational and without any focal neurological signs. This might be expected in view of the short histories, but it should be noted that one patient (Case No. 199) had already reached the "intermediate" stage by the eighth day of his illness, while four were already sufficiently delirious or comatose to render them 
TABLE I

LENGTH OF ONSET, HIGHEST C.S.F. CELL COUNTS, INCIDENCE OF RAPID REMISSION OF SYMPTOMS, AND OUTCOME IN NINE CASES

\begin{tabular}{|c|c|c|c|c|c|c|c|c|}
\hline \multirow[b]{2}{*}{$\begin{array}{l}\text { Case } \\
\text { No. }\end{array}$} & \multirow[b]{2}{*}{ Sex } & \multirow[b]{2}{*}{ Age } & \multicolumn{2}{|c|}{ Duration of Symptoms } & \multirow{2}{*}{$\begin{array}{l}\text { Maximum Cells } \\
\text { (C.S.F.) before } \\
\text { Treatment }\end{array}$} & \multirow{2}{*}{$\begin{array}{c}\text { Stage of } \\
\text { Disease when } \\
\text { Treatment Begun }\end{array}$} & \multirow{2}{*}{$\begin{array}{c}\text { Rapid } \\
\text { Relief of } \\
\text { Symptoms }\end{array}$} & \multirow[b]{2}{*}{ Result } \\
\hline & & & $\begin{array}{c}\text { Before } \\
\text { Admission } \\
\text { (days) }\end{array}$ & $\begin{array}{c}\text { Before } \\
\text { Treatment } \\
\text { Begun (days) }\end{array}$ & & & & \\
\hline 8 & M. & 18 & 5 & 8 & 500 & Early & Yes & Recovered \\
\hline 60 & M. & 36 & 6 & 6 & 1,600 & Late & Yes & Recovered \\
\hline 65 & M. & 6 & 7 & 7 & 514 & Early & Yes & Recovered \\
\hline 89 & M. & 15 & 7 & 21 & 740 & Late & Yes & Died \\
\hline 110 & F. & 18 & 2 & 4 & 500 & Early & Yes & Recovered \\
\hline 168 & M. & 11 & $8^{*}$ & 19 & 1,070 & Late & Yes & Recovered \\
\hline 196 & M. & 19 & 3 & 19 & 1,300 & Early & Yes & Recovered \\
\hline 199 & M. & 27 & 4 & 7 & 890 & Intermediate & Yes & Recovered \\
\hline 118 & M. & 19 & 1 & 8 & 100 & Late & No & Died \\
\hline
\end{tabular}

* Meningitis diagnosed by private doctor on seventh day of illness.

completely inaccessible. In two cases (Nos. 89 and 168) this was due to delay in diagnosis and consequently in the institution of chemotherapy, but in both the others the disease had reached the "advanced" stage by the eighth day, and in one of these (Case No. 118) it ran its full course to death in only 10 days. The other patients recovered completely. The follow-up period for this group varies between one and seven years.

The typical clinical picture is shown by the following case :-

Case No. 196.-A young National Serviceman aged 19 years reported sick on September 8, 1953. He complained that for the past two days he had been feeling unwell, that his back had been stiff, and that he had had a dull, aching pain between the shoulders. On examination he was found to be feverish, but there were no other abnormal physical signs. He was admitted to hospital, and two days later he developed a moderately severe frontal headache. This persisted, and on September 13, just seven days after he first began to feel ill, it was noticed that his neck was stiff. A diagnostic lumbar puncture was therefore performed which yielded a fluid under a pressure of $130 \mathrm{~mm}$. C.S.F. containing 1,300 cells per c.mm., of which $60 \%$ were mononuclears. The protein content was $320 \mathrm{mg}$. per $100 \mathrm{ml}$., the sugar 60 mg. per $100 \mathrm{ml}$., and the chloride 760 per $100 \mathrm{ml}$. In view of the normal sugar and chloride contents, a tentative diagnosis was made of non- or pre-paralytic anterior poliomyelitis, and no chemotherapy was given.

Following the lumbar puncture he improved remarkably : within a few days the temperature had settled and the headache and neck stiffness disappeared. Nevertheless, a second lumbar puncture on September 17 showed that the C.S.F. still contained 1,300 cells per c.mm., of which $90 \%$ were mononuclears ; the sugar content was now $45 \mathrm{mg}$. per $100 \mathrm{ml}$. and the protein content was unchanged. A third specimen of C.S.F. obtained on September 24 gave essentially similar findings. In view of these persistent abnormalities in the C.S.F., the patient was transferred to the Military Hospital for Head Injuries on September 25.

On admission he looked so well that it was difficult to believe that he had anything seriously wrong with him. He would not admit to any headache or other symptom, and indeed frequently asked why he was being kept in hospital. There were no abnormal physical signs whatever, and, in particular, all movements of the neck were full and painless. Radiography of the chest showed no abnormality, and the Mantoux test was weakly positive to $0 \cdot 1 \mathrm{ml}$. old tuberculin 1 in 100 . However, in spite of his apparent well-being and the absence of all signs of meningeal irritation, lumbar puncture showed that the C.S.F. still contained 740 cells per c.mm., of which $99 \%$ were mononuclears ; the protein content was $560 \mathrm{mg}$. per $100 \mathrm{ml}$., and the sugar and chlorides $35 \mathrm{mg}$. and $670 \mathrm{mg}$. per $100 \mathrm{ml}$. respectively.

A provisional diagnosis of tuberculous meningitis of acute onset was made, and treatment with systemic and intrathecal streptomycin and isonicotinic acid hydrazide (I.N.A.H.) was begun immediately. The diagnosis received strong support from the estimation of the partition of bromide between serum and C.S.F. This showed that the ratio was only 1.06 , a characteristic finding in tuberculous meningitis (Taylor, Smith, and Hunter, 1954). It was not, however, confirmed until the nineteenth day of treatment, when $M$. tuberculosis was identified in a single specimen of cisternal C.S.F. Later still, $M$. tuberculosis was isolated by culture from the specimen of lumbar C.S.F. obtained on the thirteenth day of treatment.

As soon as bacteriological confirmation of the diagnosis was obtained the daily intrathecal and systemic chemotherapy was supplemented by intermittent intrathecal injections of tuberculin (Smith and Vollum, 1950; 
Smith, 1953). The spontaneous remission of symptoms was maintained, and the patient made a rapid and uninterrupted recovery.

This case exemplifies all three features which together form the syndrome under discussion. In the first place, only eight days elapsed between the first departure from normal health and the time when stiffness of the neck became sufficiently obvious to compel lumbar puncture. Secondly, the first three specimens of C.S.F. all contained more than 1,000 cells per c.mm., while even the fourth contained 740 cells per c.mm. In the first specimen, $40 \%$ of these cells were polymorphonuclears; thereafter they were virtually all mononuclears. The C.S.F. findings in this case also differed from those typical of tuberculous meningitis in that the sugar and chloride contents at the first three examinations were within the limits of normal. Thirdly, there was a well-marked spontaneous remission of both signs and symptoms. This preceded the institution of chemotherapy by no less than two weeks, in spite of the fact that the meningeal infection remained active, as shown unequivocally by the isolation of $M$. tuberculosis on two separate occasions during the fifth and sixth weeks of the illness. Finally, this early remission led on uninterruptedly to a permanent recovery with appropriate chemotherapy.

\section{Diagnosis}

As this case shows, diagnosis can be extremely difficult. This difficulty is reflected by the interval between the patients' first admission to hospital and the time when treatment was begun (Table I). The problem of diagnosis in tuberculous meningitis in general has been discussed elsewhere (Smith and Vollum, 1954), and in this group of cases the differential diagnosis has included acute purulent meningitis and subarachnoid haemorrhage (Cases No. 110 and 60), non-paralytic poliomyelitis (Case No. 196), intracranial haemorrhage and brain abscess (Case No. 168), frontal sinusitis and hysteria (Case No. 8), and benign chorio-lymphocytic meningitis (Cases Nos. 8 and 89 ). It is this last condition that is perhaps the most confusing, and differentiation is made the more difficult by the tendency in the acute tuberculous cases for symptoms to remit spontaneously. Even when treatment is withheld the patient's improvement may still be such as to appear to clinch the diagnosis in favour of benign chorio-lymphocytic meningitis. The fact that remission is only temporary may then not be appreciated until too late. The following case illustrates the difficulties in diagnosis that may be encountered and the dangers to which the patient may consequently be exposed.
Case No. 8. - This case has already been described by Smith, Vollum, and Cairns (1948, Case 8).

A young aircraftman aged 18 years was transferred from another hospital to the Military Hospital for Head Injuries, Wheatley, on April 26, 1947. Ten days earlier he had felt a little unwell and thought he had caught a cold in his head. Three days later, on April 19, he went home on leave and that same day developed severe frontal headache and a purulent nasal discharge. He went to bed and was treated by his family doctor for acute frontal sinusitis. The nasal discharge cleared up in about three days, but the headache grew steadily worse until it became so intense that it prevented him from sleeping, and indeed at times was almost unbearable. The pain also began to spread down the neck. He began to vomit and became extremely restless.

After five days he was admitted to the Casualty Reception Station belonging to his unit. At this stage he was restless and moaning and plucking at his bedclothes. No clear account of his symptoms could be obtained, but his chief complaints seemed to be giddiness, lack of sleep, and repeated vomiting. He was apyrexial, and no abnormal physical signs were detected. This same day he began to have intermittent attacks of double vision. It was thought that his symptoms were psychogenic, and the next day he was transferred to the Q.A. Military Hospital, Milbank. There he was found to have a temperature of $101^{\circ} \mathrm{F}$. and was moaning from the intensity of his headache. There were no other abnormal findings. On lumbar puncture the C.S.F. was found to be under increased pressure and to contain 50 mononuclears per c.mm. The sugar was reduced and the chloride content $635 \mathrm{mg}$. per $100 \mathrm{ml}$. He was transferred to us the following day.

On admission he was feverish and looked ill and flushed. Although he was in great distress from his headache, he was able to give a fairly detailed history and to cooperate in a full examination. Except for moderate stiffness of the neck, this showed no abnormality whatever. Radiographs of the chest and skull were normal. Lumbar puncture yielded a fluid under a pressure of well over $300 \mathrm{~mm}$. C.S.F. and containing 600 cells, of which $98 \%$ were mononuclears, protein $360 \mathrm{mg}$. per $100 \mathrm{ml}$., and chlorides $680 \mathrm{mg}$. per $100 \mathrm{ml}$. Not enough C.S.F. was obtained for estimation of the sugar. A provisional diagnosis of tuberculous meningitis was made and treatment with systemic and intrathecal streptomycin was begun on April 27.

Almost at once he began to improve, and within a few days was virtually free from symptoms. The daily cell counts in the C.S.F. ranged between 830 per c.mm. and 391 per c.mm., and all showed virtually $100 \%$ of mononuclears, while no acid-fast bacilli were identified in spite of repeated and prolonged examination of every specimen. We therefore concluded that we had made a mistake in diagnosis and that this was really a case of benign chorio-lymphocytic meningitis. The streptomycin was accordingly withheld on May 3, after one week of treatment.

During the next few days there was little change, except that the patient was perhaps not quite so well in 
that he again began to have occasional attacks of headache, vomiting, and diplopia. On May 13 the culture set up from the specimen of C.S.F. obtained on April 26that is to say, from our original specimen-was found to be positive for $M$. tuberculosis. Treatment was immediately begun again, but, even so, two days later the patient developed a mild right-sided hemiparesis which over the next five days became almost complete. Treatment was continued, and after a long and difficult illness he made a complete recovery except for a residual right hemiparesis and dysphasia.

This was the first of our cases in which this particular syndrome was seen. The short history, the absence of any evidence of systemic tuberculosis, the high cell counts, which were almost $100 \%$ lymphocytic, the repeated failure to identify acidfast bacilli on the films, and, above all, the rapid remission of symptoms during the first week of treatment, led us to substitute a diagnosis of benign chorio-lymphocytic meningitis for our original-and correct-one of tuberculous meningitis. In all probability this mistake cost the patient the full use of his right hand and, had it not been that cultures of the very first specimen of C.S.F. fortunately proved positive, might well have cost him his life.

It is interesting to recall that Trousseau (1867) commented on the marked but transient clinical improvement occasionally seen in cases of tuberculous meningitis and warned the inexperienced not to be deceived by this into adding to the distress of the relatives by changing a bad for a falsely good prognosis. Today the penalty for the same mistake is greater, since it may change a really good prognosis into an unnecessarily bad one.

In these, as in other cases of tuberculous meningitis, the final proof of the diagnosis rests with the bacteriologist. In the case just quoted only single positive cultures were ever obtained, and no organisms were ever identified on examination of the direct films of the lumbar C.S.F. In almost all the other cases acid-fast bacilli were found on films from early specimens of C.S.F. and were often present in quantity. It must, however, be remembered that unless tuberculous meningitis is suspected the appropriate staining and cultural methods may not be used in examination of the C.S.F., when the true nature of the infection will be overlooked.

\section{Changes in the Cerebrospinal Fluid}

With one exception the cellular changes in the C.S.F. in these acute cases differed both in quality and degree from those commonly seen in tuberculous meningitis. Accepted limits for the pleocytosis in tuberculous meningitis are 25 to 500 (Merritt and Fremont-Smith, 1937), 10 to 350 (Brain, 1951), and 35 to 300 (Debré and Brissaud, 1953). Other authors confirm these values. All agree that lymphocytes predominate, though as a rule a certain number of polymorphonuclear leucocytes are also present (Smith and Daniel, 1947). The total and differential cell counts before treatment in our cases are shown in Table II. In five cases the C.S.F. at the first lumbar puncture contained over 700 cells per c.mm., and in three there were more than 1,000 cells per c.mm. By the time the first intrathecal injection was given cell counts of 500 per c.mm. or more had been seen in every case but one. Not infrequently these high counts were maintained or even increased during the first days of treatment, but thereafter they usually fell until by the third or fourth week of treatment they were varying within the accepted range (Fig. 1).

TABLE II

TOTAL AND DIFFERENTIAL CELL COUNTS AND PROTEIN CONTENTS OF C.S.F. BEFORE TREATMENT

\begin{tabular}{|c|c|c|c|c|c|c|c|c|c|c|}
\hline \multirow{3}{*}{$\begin{array}{l}\text { Case } \\
\text { No. }\end{array}$} & \multicolumn{10}{|c|}{ C.S.F. Cell Counts (per c.mm.) and Protein (mg. $/ 100 \mathrm{ml}$.) } \\
\hline & \multicolumn{5}{|c|}{ First Lumbar Puncture } & \multicolumn{5}{|c|}{ Outset of Treatment } \\
\hline & $\begin{array}{l}\text { Total } \\
\text { Cells }\end{array}$ & $\begin{array}{c}\text { Polys. } \\
\text { (\%) }\end{array}$ & $\underset{(\%)}{\text { Monos. }}$ & Protein & $\begin{array}{l}\text { Day of } \\
\text { Illness }\end{array}$ & $\begin{array}{l}\text { Total } \\
\text { Cells }\end{array}$ & $\begin{array}{c}\text { Polys. } \\
(\%)\end{array}$ & $\underset{(\%)}{\text { Monos. }}$ & Protein & $\begin{array}{l}\text { Day of } \\
\text { Illness }\end{array}$ \\
\hline 8 & 50 & $\mathbf{0}$ & 100 & - & 7th & 674 & 2 & 98 & 450 & 9th \\
\hline 60 & 1,600 & 17 & 83 & 840 & 6th & & $\mathbf{S}$ a & $d a y$ & & \\
\hline 65 & 514 & 11 & 89 & 210 & 7th & & S a $n$ & d a y & & \\
\hline 89 & 740 & 1 & 99 & 180 & 19th & 391 & 58 & 42 & 280 & $21 \mathrm{st}$ \\
\hline 110 & 469 & 28 & 72 & 105 & 2nd & 500 & 9 & 91 & 90 & 4th \\
\hline 168 & 1,070 & 82 & 18 & 50 & 8th & $600^{*}$ & 24 & 76 & 120 & 18 th \\
\hline 196 & 1,300 & 40 & 60 & 320 & 8th & 742 & 1 & 99 & 560 & 19 th \\
\hline 199 & 891 & 6 & 94 & 200 & 7th & & $S$ a $n$ & d a y & & \\
\hline 118 & 88 & \multicolumn{2}{|c|}{ No differential } & 200 & 5th & 100 & 0 & 100 & 200 & 8th \\
\hline
\end{tabular}

* Burr-holes introduced on the previous day. 
Fig. 1.-Graph of the behaviour of cells and protein in the C.S.F. under treatment of Case No. 110 (Smith and Vollum, 1954, Case 1).
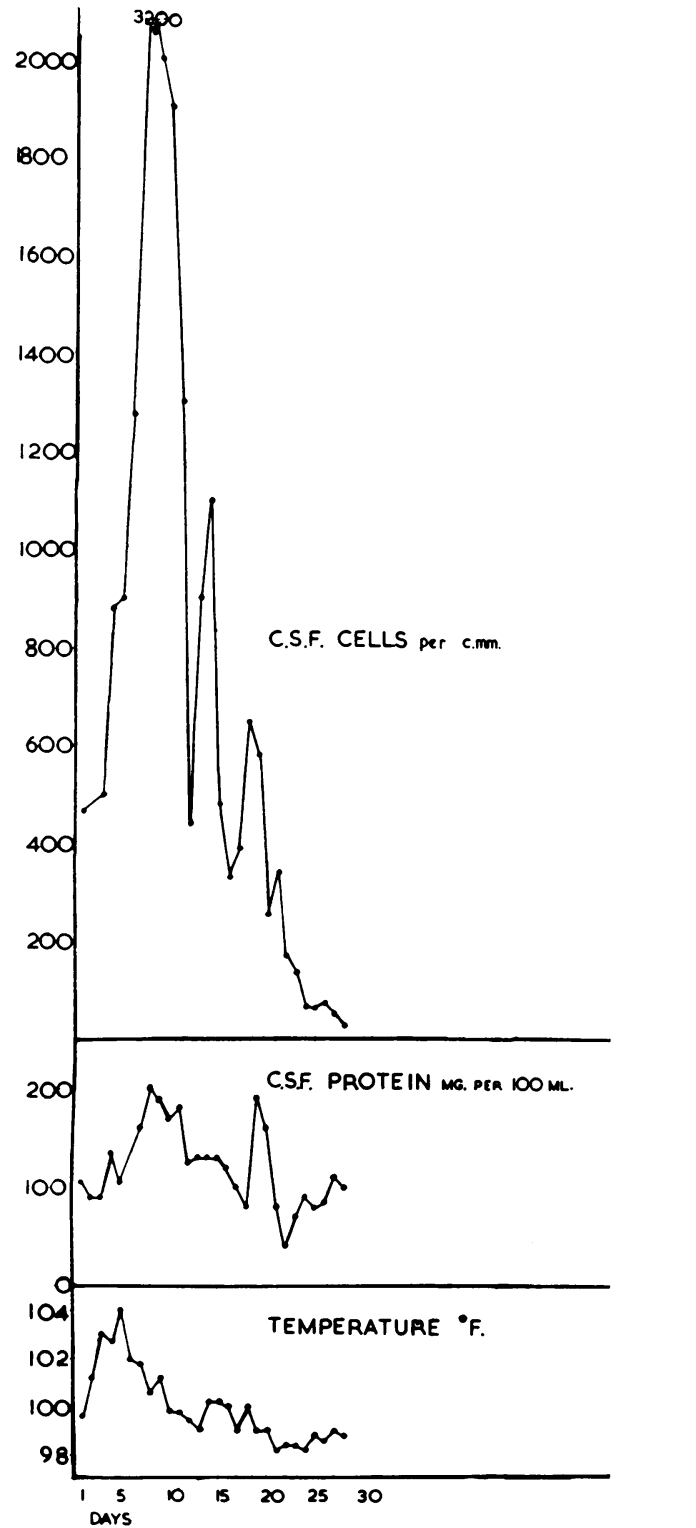

In three cases the cells at the time of the first lumbar puncture were virtually all lymphocytes, but in the other four for which full details are known there was a considerable number of polymorphonuclear leucocytes present, and in one case the proportion was as high as $82 \%$. But, with one exception, the number of polymorphonuclear leucocytes rapidly decreased as the illness lengthened, until, by the time that treatment was begun, the
TABLE III

DETAILS OF C.S.F. FINDINGS IN CASE 196 BEFORE TREATMENT

\begin{tabular}{c|c|c|c|c|c}
\hline $\begin{array}{c}\text { Day of } \\
\text { Illness }\end{array}$ & $\begin{array}{c}\text { Total Cells } \\
\text { (per c.mm.) }\end{array}$ & $\begin{array}{c}\text { Polymorphs } \\
(\%)\end{array}$ & Protein & Sugar & Chlorides \\
\cline { 1 - 3 } 8th & 1,300 & 40 & 320 & 60 & 760 \\
11th & 1,300 & 10 & 320 & 45 & 720 \\
18 th & 1,100 & 10 & 300 & 40 & 730 \\
19th & 740 & 1 & 560 & 35 & 670 \\
\hline
\end{tabular}

pleocytosis was predominantly, if not entirely, lymphocytic. This disappearance of the polymorphonuclear fraction was well seen in Case 196 (Table III), the only case in which serial punctures were done before the institution of chemotherapy.

The Pathogenesis of the Syndrome of Tuberculous Meningitis of Acute Onset

We have previously presented evidence that the C.S.F. changes of tuberculous meningitis as a whole are the expression of an antibody-antigen reaction : that they are, in fact, the result of an intrathecal tuberculin reaction or series of reactions (Cairns and Smith, 1952 ; Taylor and others, 1954). The close resemblance between the findings in these acute cases and those of the experimental intrathecal tuberculin reaction lends strong support to this hypothesis.

Provided that the recipient is sufficiently sensitive to tuberculin to give a moderate intradermal reaction to $0.1 \mathrm{ml}$. of old tuberculin 1 in $1,000,0.75 \mu \mathrm{g}$. of the purified protein derivative of tuberculin (P.P.D.) injected intrathecally causes changes in the C.S.F. indistinguishable from the classical findings in tuberculous meningitis (Smith and Vollum, 1950, Fig. 7). When, however, rather larger amounts of P.P.D. $(3.75 \mu \mathrm{g}$.) are injected the consequent changes in the C.S.F. are greatly accentuated and then mimic very closely those seen in these cases of tuberculous meningitis of acute onset (Fig. 2: Swithinbank, Smith, and Vollum, 1953, Fig. 1b). This suggests, therefore, that the pathogenesis in these acute cases is the sudden rupture of a comparatively large caseous focus, or "Rich's focus" (Rich and McCordock, 1933), with release of its contents into the C.S.F. These contents will not only be impregnated with tuberculin but will also contain tubercle bacilli which are themselves antigenic. The first result of this rupture will be to flood the C.S.F. with tuberculin-containing material which will then provoke a brisk intrathecal tuberculin reaction. This reaction would be expected to subside in a matter of days, but in the meantime the living $M$. tuberculosis will be seeding themselves in the subarachnoid pathways where, sooner or later, they will 
Fig. 2.-The diphasic pleocytosis of the complete intrathecal tuberculin reaction in the normal meninges.

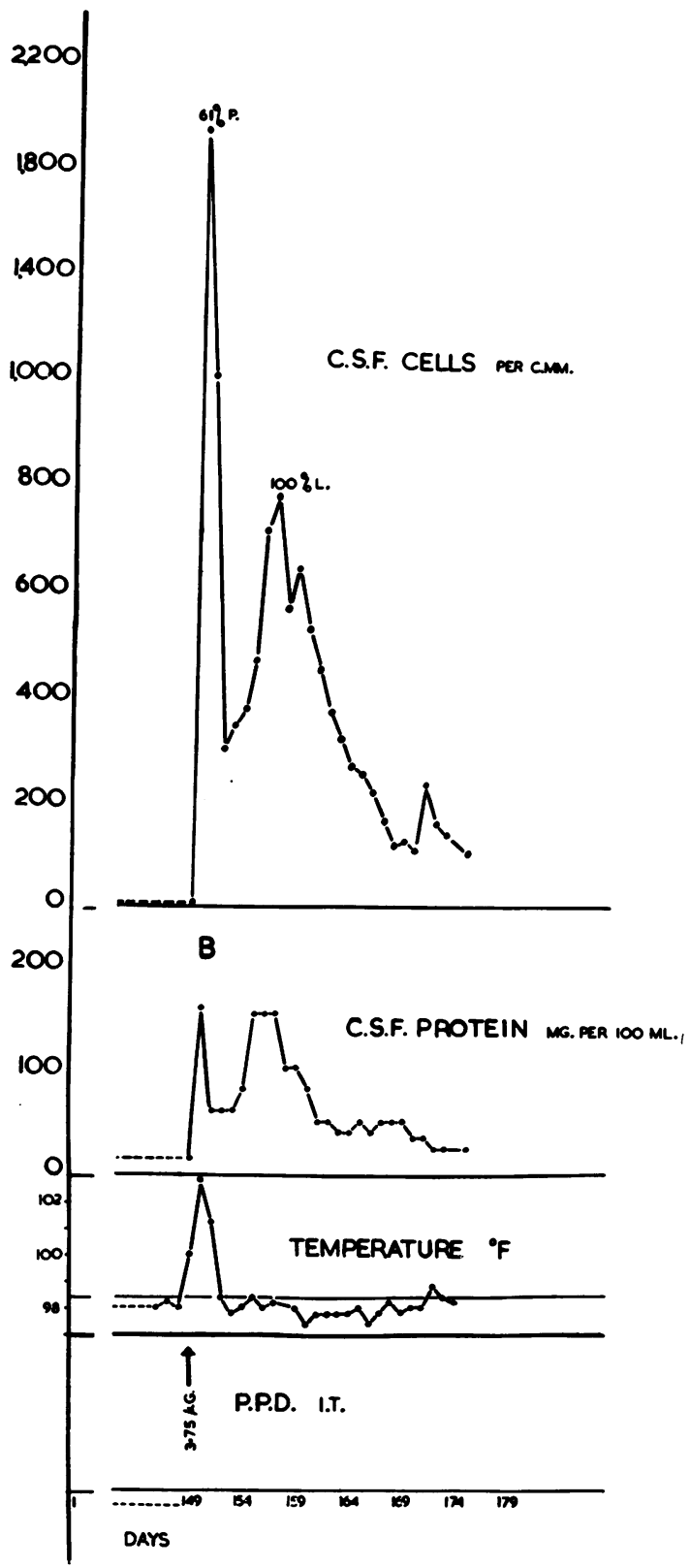

set up a true " caseous tuberculous" meningitis (Lincoln, 1947) with all its established clinical and C.S.F. characteristics.

Both the clinical and C.S.F. pictures in tuberculous meningitis of acute onset can be adequately explained on this hypothesis. The abrupt onset of the signs and symptoms of a mild to moderate meningeal inflammation, without focal neurological signs, is the rule in both the experimental intrathecal tuberculin reaction and of tuberculous meningitis of acute onset. Similarly, the rapid remission of symptoms seen in these acute cases corresponds closely with the cessation of the clinical signs of meningitis seen during the experimental reaction. The only difference is that in the sterile reaction this remission is permanent, while in the natural disease the symptoms of the intrathecal reaction itself are, in the absence of effective treatment, ultimately succeeded by those of an established meningitis. at

The correspondence between the C.S.F. findings in tuberculous meningitis of acute onset and those of the fully developed tuberculin reaction is equally precise. During the first 24 hours of the experimental reaction the C.S.F. contains many hundreds, or even thousands, of cells of which the majority are polymorphonuclear leucocytes. In none of our acute cases has the C.S.F. been examined within 24 hours of the onset of symptoms, but, even so, exceptionally high cell counts with, sometimes, a high proportion of polymorphonuclear leucocytes have been seen (Table II). Similarly, when the C.S.F. has been examined a few days after the onset of symptoms the total cell count may still be very high, though the differential count shows that almost all the cells are now lymphocytes (Table III), and this is exactly what is found when the C.S.F. is examined towards the end of the first week of the experimental reaction. The protein content of the C.S.F. is also of the same order in the two conditions.

That a leak of the contents of a tuberculoma can cause a reaction in the C.S.F. indistinguishable from that seen in tuberculous meningitis of acute onset is shown by the following case :

Case No. 74. - This case has also been described by Cairns (1951, Case 1).

A man of 40, who was known to be suffering from bilateral chronic fibro-caseous pulmonary tuberculosis, was admitted to the Radcliffe Infirmary on August 8, 1949 , with a three to four weeks' history of morning headache and vomiting. (This case is not, of course, included in our group of cases of acute onset.) Physical examination revealed no abnormal neurological signs whatever. The diagnosis was therefore thought to lie between early tuberculous meningitis and a massive tuberculoma in a silent area of the brain. A cautious lumbar puncture was performed which yielded a fluid under a pressure of $200 \mathrm{~mm}$. C.S.F. containing no cells and $100 \mathrm{mg}$. of protein per $100 \mathrm{ml}$. Examination of a direct film of the fluid, however, revealed one acid-fast bacillus. This seemed to confirm the diagnosis of early tuberculous meningitis, and treatment with daily intrathecal and intramuscular injections of streptomycin was accordingly begun. The C.S.F. showed no significant change for five 
consecutive days and then, on the sixth day of treatment, the cell count suddenly increased to over 700 cells per c.mm., of which $96 \%$ were polymorphonuclear leucocytes. This sudden spike in the cell count subsided almost as rapidly as it arose but was later succeeded by several others, in most of which the cell counts rose to well above 3,000 or even 4,000 cells per c.mm. and of which one, the highest, was accompanied by the sudden appearance of a very large number of tubercle bacilli on the direct film.

Towards the end of the second month of treatment the patient developed a mild right-sided hemiparesis. A little later unmistakable signs appeared of raised intracranial pressure, the patient became decerebrate, and in spite of a sub-temporal decompression he died.

At necropsy no evidence of meningitis was found, other than a minimal milky opacity of the basal meninges. There was, however, a huge tuberculous abscess in the left parietal lobe impinging on a sulcus and filled with liquid pus. When films of this pus were stained by the Ziell-Neelsen method they were scarlet to the naked eye from the enormous numbers of $M$. tuberculosis that were present.

In this case the leaking contents of the tuberculous abscess had provoked a series of intrathecal tuberculin reactions in which the C.S.F. changes bore an unmistakable resemblance to those seen both in the experimental intrathecal tuberculin reaction and in tuberculous meningitis of acute onset.

Confirmatory evidence that the syndrome of tuberculous meningitis of acute onset is the expression of an intrathecal tuberculin reaction is provided by Case No. 118, the only one of our acute cases in which the patient died during the early phase of the illness and where therefore the pathological changes of the presumed spontaneous tuberculin reaction could be studied.

Case No. 118. - A young National Serviceman aged 19 years was admitted from a hospital in Germany to the Military Hospital for Head Injuries late in the evening of February 8, 1951. For the past four months he had been treated with testosterone for an established Fröhlich's syndrome, and during this time had lost $46 \mathrm{lb}$. in weight. This loss was attributed to the endocrine therapy until February 1, when he began to complain of severe headache and difficulty in finding words. He was admitted to hospital, where he was found to be a little feverish and to be mentally dull and apathetic and to have a mild right hemiparesis with dysphasia. Radiological appearances of the lung fields suggested miliary tuberculosis. Lumbar puncture yielded a fluid under a pressure of $300 \mathrm{~mm}$. C.S.F. and containing 88 leucocytes per c.mm. (nature of cells not recorded) and $200 \mathrm{mg}$. of protein per $100 \mathrm{ml}$.

During the next few days there was little change in his condition except that the fever increased, and on the eighth day of his illness he seemed fairly well and was quite alert and able to talk. On this day he was flown home to England, and while in the aeroplane he grew

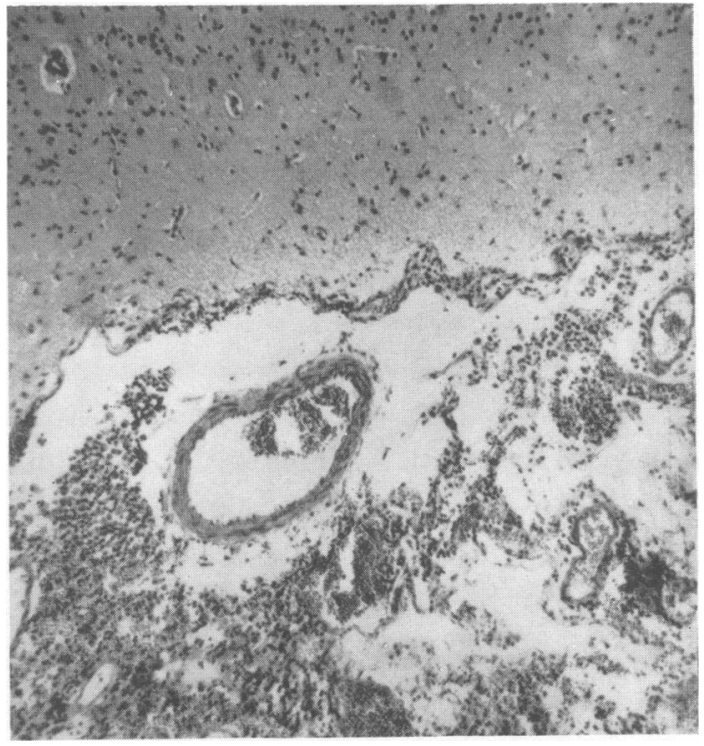

Fig. 3.-Meningeal exudate in Case No. 118.

rapidly worse and by midday was in coma. A lumbar puncture at this time showed that the C.S.F. was again under a pressure of $300 \mathrm{~mm}$. C.S.F., and analysis of the fluid done after arrival at Wheatley showed that it contained 100 lymphocytes per c.mm., $200 \mathrm{mg}$. protein per $100 \mathrm{ml}$., while the chloride and sugar contents were $560 \mathrm{mg}$. and $22 \mathrm{mg}$. per $100 \mathrm{ml}$. respectively.

On admission to the Military Hospital for Head Injuries he was profoundly unconscious; the pupils were widely dilated and fixed to light, and the corneal reflexes were absent. The neck was a little stiff, but Kernig's sign was negative. There was no definite papilloedema. The depth of coma made detailed examination impossible, but there was certainly some degree of right hemiparesis. The tone in both lower limbs was increased, and there was a bilateral ankle and patellar clonus. Radiographs of the chest showed the characteristic changes of miliary tuberculosis, and on subsequent retinoscopy choroidal tubercles were identified in each eye.

In the early hours of the next morning the lateral ventricles were tapped through bifrontal burr-holes as an emergency measure. The ventricles were symmetrical and the intraventricular pressure was $200 \mathrm{~mm}$. C.S.F. While the patient was in the theatre a message was received that acid-fast bacilli had been found in the specimen of C.S.F. withdrawn during the flight, and accordingly $100 \mathrm{mg}$. of streptomycin was instilled into the ventricles. $M$. tuberculosis were later identified in the specimen of ventricular fluid.

Following the ventricular tap the patient at first improved a little, but at 8 o'clock on the morning of February 9 he had an attack of decerebrate rigidity in which his temperature rose rapidly to $105^{\circ} \mathrm{F}$., the pulse to 160 , and respirations to 54 per minute. The hyperpyrexia was controlled by means of an iced rectal drip, 


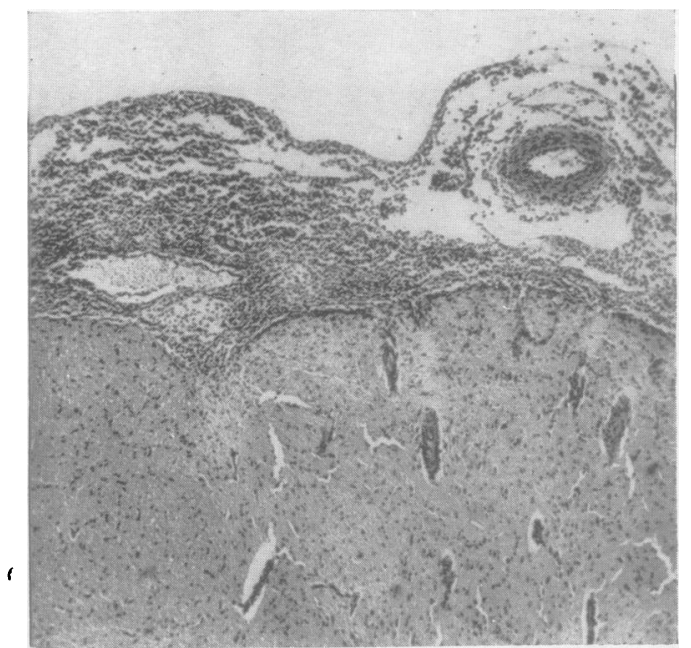

Fig. 4.-Meningeal exudate in a guinea-pig in the course of an intrathecal tuberculin reaction.

and the patient again improved a little. However, by midday the decerebrate posture was again becoming apparent, and during the rest of the day his general condition steadily deteriorated. He again developed a hyperpyrexia, and just after midnight, at the beginning of the tenth day of his illness, he died.

At necropsy the widespread miliary tuberculosis was confirmed. But to everyone's surprise the naked-eye appearances of the brain were entirely normal; in particular, no tubercles or basal exudate could be seen. When the brain was cut after fixation the absence of any macroscopic abnormalities was confirmed. However, when the stained sections were examined the subarachnoid space was seen to be distended by a profuse generalized cellular exudate (Fig. 3).

According to the hypothesis outlined above, this patient died at the height of a fulminating intrathecal tuberculin reaction. Except for the fatal termination, the clinical events of the last 36 hours of the illness were identical with those twice seen when excessive amounts of P.P.D. were inadvertently given in the treatment of tuberculous meningitis (Smith and Vollum, 1950). Even more conclusive were the post-mortem findings. Not only was the complete absence of any macroscopic changes in the brain in striking contrast to the findings in all our other fatal cases of tuberculous meningitis, but the microscopic appearances were quite remarkably like those seen in experimental animals that had been sensitized to tuberculin and then given an intrathecal injection (Fig. 4) of a large amount of P.P.D. (Bosanquet, Daniel, and Vollum, Fig. 3, 1953).

\section{Discussion and Conclusions}

The explanation offered above for the syndrome of tuberculous meningitis of acute onset is thus sup- ported by a considerable body of circumstantial evidence. In the first place, it explains both the abrupt onset and the tendency to spontaneous remission. Moreover, since it has been shown that intrathecal tuberculin is a valuable adjuvant to the chemotherapy of tuberculous meningitis (Smith, 1953), it may help to explain why the prognosis in this group of cases is good, provided that treatment is begun before the patient is moribund. Secondly, it is supported by the marked similarity between the C.S.F. changes in cases of acute onset and those of the experimental intrathecal reaction. Thirdly, it has been shown that a tuberculoma leaking into the C.S.F. is capable of producing changes in the C.S.F. that are strictly comparable with those under discussion. And, finally, the pathological findings when death occurred at the height of the supposed reaction not only differed profoundly from the classical post-mortem findings in tuberculous meningitis, but bore an unmistakable resemblance to those seen in experimental animals killed at the height of an induced tuberculin reaction.

This conclusion, that the syndrome of tuberculous meningitis of acute onset is caused by a particularly well-marked spontaneous tuberculin reaction, supports the hypothesis that the C.S.F. changes in tuberculous meningitis as a whole are a manifestation of a hypersensitivity phenomenon, since it explains so well the anomaly of the unusually high cell count.

The other well-established anomalous finding in some cases of proven tuberculous meningitis of trivial or absent abnormalities in the C.S.F. can also be explained on the same basis. If this hypothesis holds, then a normal, or virtually normal, C.S.F. would be expected either if the patient had for any reason lost the power of reacting to tuberculin (Rich, 1951), or if the meningeal involvement was confined to the depths of a sulcus and did not invade the subarachnoid space as a whole. As it happens,

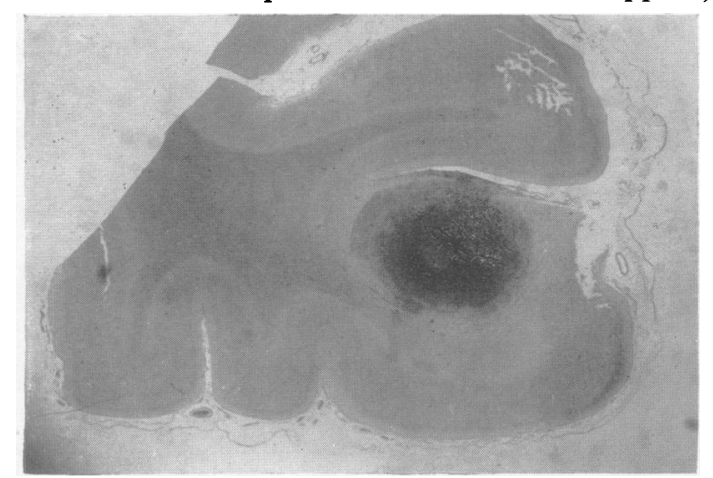

Fig."5.-Tuberculoma impinging on a sulcus, with overlying exudate. The meninges were normal. 
we have seen examples of both these conditions. We have seen a case of overwhelming miliary tuberculosis in which the patient was not only Mantoux negative to $0.1 \mathrm{ml}$. old tuberculin 1 in 100 , but in which both the cell and protein contents of the C.S.F. returned to normal during the first five days in hospital, leaving $M$. tuberculosis present in the C.S.F. as its only abnormality. As the patient improved under the influence of chemotherapy and cortisone, so the Mantoux test became positive and the typical C.S.F. changes reappeared. We have also seen a case of miliary tuberculosis where death occurred in the eighth week of treatment and in which lumbar puncture was regularly performed every week. The C.S.F. was last examined one week before death and was normal in all respects by the strictest standards. Yet at necropsy the brain was found to be studded with small tuberculomata, and though many of these were impinging on the subarachnoid space, and one had actually leaked into a sulcus, the meninges as a whole were perfectly normal (Fig. 5).

We therefore conclude that the C.S.F. changes in tuberculous meningitis as a whole are the expression of an antibody-antigen response, or, more specifically, of a series of intrathecal tuberculin reactions, and that not only the classical C.S.F. findings but both the well established anomalous findings can be explained in this way.

\section{Summary}

The syndrome of tuberculous meningitis of acute onset, when complete, consists of an acute or abrupt onset, a tendency to spontaneous remission, unusually high cell counts in the C.S.F., and a good prognosis on adequate treatment.

Evidence is put forward which strongly suggests that the syndrome is caused by a sudden spontaneous intrathecal tuberculin reaction due to rupture of a Rich's focus.

The pathogenesis of the C.S.F. changes in tuberculous meningitis is discussed in relation to these findings.

We are grateful to the War Office for permission to publish some of the cases included in this paper.

\section{REFERENCES}

Bosanquet, F. D., Daniel, P. M., and Vollum, R. L. (1953). Brit. J. exp. Path., 34, 376.

Brain, W. R. (1951). Diseases of the Nervous System, 4th ed. Oxford Univ. Press, London.

Cairns, H. (1951). Arch. Dis. Childh., 26, 373.

- and Smith, H. V. (1952). Modern Practice in Tuberculosis, ed. T. H. Sellors and J. L. Livingstone, vol. 2, p. 353. Butterworth, London.

Debré, R., and Brissaud, H-E. (1953). Méningite tuberculeuse et tuberculose miliaire de l'enfant. Masson, Paris.

Lincoln, E. M. (1947). Amer. Rev. Tuberc., 56, 75.

Medical Research Council Report (1948). Streptomycin in Tuberculosis Trials Committee. Lancet, 1, 582 .

Merritt, H. H., and Fremont-Smith, F. (1937). The Cerebrospinal Fluid. Saunders, Philadelphia.

Rich, A. R. (1951). The Pathogenesis of Tuberculosis, 2nd ed. Blackivell, Oxford.

-, and McCordock, H. A. (1933). Bull. Johns Hopk. Hosp., 53,5 .

Smith, H. V. (1953). Proc. roy. Soc. Med., 46, 588.

- , and Daniel, P. (1947). Tubercle, 28, 64

Vollum, R. L., and Cairns, H. (1948). Lancet, 1, 627. and Vollum, R. L. (1950). Lancet, 2, 275.

二, and , (1954). Brit. med. Bull., 10, 140.

Swithinbank, J., Smith, H. V., and Vollum, R. L. (1953). J. Path. Bact., $65,565$.

Taylor, K. B. (1954). Tubercle, 35, 126.

Taylor, L. M., Smith, H. V., and Hunter, G. (1954). Lancet, 1, 700.

Trousseau, A. (1867). Lectures on Clinical Medicine. Hardwicke, London. 